\title{
Internal medicine and emergency admissions: from a national hospital discharge records (SDO) study to a regional analysis
}

\author{
Filomena Pietrantonio, ${ }^{1}$ Laura Piasini, ${ }^{2}$ Federico Spandonaro ${ }^{2}$ \\ ${ }^{1}$ Department of Medicine 1, S. Eugenio Hospital, Roma; ${ }^{2}$ Tor Vergata University of Rome, C.R.E.A. Sanità (Consortium for \\ Applied Health Economics Research), Roma, Italy
}

\begin{abstract}
In Italy, the number of internists has grown by 10\% since 1990 reaching 11,435 units, they manage 39,000 beds in 1060 Internal Medicine (IM) wards. The Internists are expected to ensure a cost-effective management of poly-pathological and complex patients. A collaborative study between the Federation of Associations of Hospital Doctors on Internal Medicine (FADOI) and the Consortium for Applied Health Economics Research (C.R.E.A. Sanità) based on data from hospital discharge records has been conducted starting from November 2014. In this article the preliminary results are shown with focus on emergency admissions characteristics to contribute to define the role of hospital IM. Evaluation is performed comparing emergency and planned admissions, IM impact on hospital admissions, availability of community-based healthcare services, diagnosis-related groups (DRGs) weight in IM and regional differences in managing hospital admissions with focus on IM department. In $2013 \mathrm{IM}$ wards discharged $1,073,526$ patients $(16.18 \%$ of the total discharged by hospitals) with a total economic value of $3,426,279.88 €$ (average DRG $3882.80 €$, from 3682.19 to 4083.42 ). The average length of stay (LOS) in IM was 9.3 days. IM covers $27 \%$ of admissions from Emergency Room. Determinants significantly affecting the emergency admissions are old age and comorbidities of the patients that also have a role in increasing LOS. 55\% of Italian hospital admissions are emergency admissions. Hospitalization rates in emergency are systematically higher than those in election and the greatest differences are in the regions with inefficiently organized regional network. The role of the hospital IM appears central in the offer of beds to the emergency room by accepting $27 \%$ of urgent admissions. The increasing impact of IM on hospital management will put the internists as authoritative stakeholders in health policy.
\end{abstract}

\section{Background}

In Italy, the number of Internists has grown by $10 \%$ since 1990 reaching 11,435 units. They manage 39,000 beds handling more than 1 million admissions in 1060 hospital Internal Medicine (IM) wards. ${ }^{1}$ The internists are expected to ensure cost-effective management of complex patient, reducing the fragmented

Correspondence: Filomena Pietrantonio, Department of Medicine 1, S. Eugenio Hospital, ASL Roma C, via Ebe Stignani 20, 00128 Roma, Italy.

Tel.: +39.06.5089501 - Fax: +39.06.5089501.

E-mail: filomena.pietrantonio@gmail.com

Key words: Hospital discharge records (SDO); acute complex patients; emergency admissions.

Received for publication: 20 November 2015.

Revision received: 1 January 2016.

Accepted for publication: 9 February 2016.

This work is licensed under a Creative Commons Attribution NonCommercial 4.0 License (CC BY-NC 4.0).

(C) Copyright F. Pietrantonio et al., 2016

Licensee PAGEPress, Italy

Italian Journal of Medicine 2016; 10:157-167

doi:10.4081/itjm.2016.674 management of several specialists, that can result in a significant growth in health care costs through the increased use of technology and subsequent referrals to super-specialists. ${ }^{2}$ With the changed Italian epidemiological scenario and the increased life expectancy, the internist role ${ }^{3}$ appears particularly crucial in response to the growing pressure on the emergency department due to overcrowding.

Currently, as a result of Italian hospital health spending reviews, and the fight against inappropriate admissions, a downward trend in hospitalization has become evident. In 2014 9,526,832 hospital admissions were granted, ${ }^{4}$ corresponding to a total of $63,129,031$ days with a reduction compared to 2013 of approximately 315,000 hospitalizations $(-3.2 \%)$ and about $1,184,000$ days ( $-1.8 \%)$. Compared to 2013 the total number of acute inpatient admissions has reduced from $6,634,977$ to $6,486,438(-2.2 \%)$, with a corresponding decrease in the days of hospitalization from $44,802,526$ to $44,089,980(-1.6 \%)$; the number of Day Hospital admissions decreased by $6.4 \%$. It may be noted that from 2001 to 2006 there was a substantially constant trend, with around 13 million discharges and just over 11 million days. As of 2007 there has been a clear and steady decline, not only due to reduction policies of inappropriate hospitalization but also to the provisions of other forms of assistance. 
Among the main reasons that lead Italians to hospitals, in addition to childbirth, are cardiovascular diseases (heart failure and shock 190,101 discharges), respiratory diseases (pulmonary edema and respiratory failure 135,929 discharges), and surgery, replanting or replacement of major joints of the lower limbs (151,849 discharges).

According to the present national tariffs and the hospital discharge records (SDO) report 2014, a day in hospital is valued $456 €$. The total remuneration guaranteed by diagnosis-related groups (DRG) amounted to approximately 26.3 billion $€$ for acute patients activities, and just over 2 billion $€$ for rehabilitation activities, a slight decrease compared to the value of $€ 29.1$ billion in the previous year $(-1 \%)$ and represents between 50 to $70 \%$ of the total funding. ${ }^{5}$

In the current scenario of cuts to the hospital and strengthening of regional networks, as well as emergency room overcrowding, the first question to ask is: How is the hospital used and by whom in Italy? And also: Is the request of emergency a modifiable and containable need?

The purpose of this paper is to analyze the modalities of hospital admission in emergency to implement the current discussion on the new role of IM in the future hospital. ${ }^{6}$

\section{Limitation of the study}

This study is not intended to be inclusive of the full Emergency Room (ER) load, that is managing the ward's admissions and patients' discharges, rather we focus on patients admitted through the ER to the different hospital wards. Also it is good to point out that a certain degree of bias may result from the fact that the planned admissions, because of long waiting lists, will often be transformed into emergency admissions. Nevertheless, this analysis will be useful in understanding the main determinants of ER overcrowding and then in identifying possible room for maneuver in containing the phenomenon.

\section{Materials and Methods}

In November 2014 a collaborative study began to assess the impact of hospital IM on the activities of all Italian hospitals. A scientific cooperation agreement was made between the Consortium for Applied Health Economics Research (C.R.E.A. Sanità) and the Internal Medicine Unit 1 of S. Eugenio General Hospital in Rome for data processing of SDO provided by the Ministry of Health. All the 2013 SDO were analyzed. The analysis is intended solely for the hospital acute admissions in ordinary regime, excluding both admissions for vaginal delivery and cesarean. The objectives of the study are the following: i) evaluation of the ca- suistry in Internal Medicine (called General Medicine in the official documents); ii) allocation of patients; iii) receptivity of the field; iv) relationship with private hospitals; v) operating costs of similar diseases treated by the internist compared with the other specialists; vi) calculation of IM DRGs weight and IM DRGs value impact on the total number of DRG produced; vii) analysis of the interaction of IM with the Emergency and Primary Health Care.

\section{Results}

To date, preliminary data analyses are available describing the role of the hospital in response to the needs of patients asking to be treated in emergency.

\section{National data}

The first interesting evidence is that $55 \%$ of Italian hospital admissions come from the ER. The total acute hospital admissions in ordinary regime (without Day Hospital) in 2013 were 6,635,112. The trend confirms the reduction of admissions, evident since 2001, which fell by $4 \%$ compared to $2012 .^{7}$ The DRGs related to medical wards are 3,846,601 from which the discharged from the Internal Medicine are 1,073,525. The male/female ratio is $49 / 51 \%$. Discharged patients from the Internal Medicine represent $16.18 \%$ of the total number of discharged. The IM is responsible for $28 \%$ of the discharge related to medical wards.

The top 10 DRG had a rate among $1600 €$ and $5492 €$, and an average weight between 0.7 and 1.62. The first and second DRGs are heart failure and pulmonary edema. The top 10 DRGs represent $5 \%$ of the total value of admissions and IM DRGs represent $13.92 \%$, thus showing the complexity and weight on the IM patients. On the first 10 DRG $6 \%$ was transferred to the field, $75 \%$ discharged and deaths were $14 \%$. The national average length of stay in IM in 2013 was 9.28 (range 7 to 13 days).

\section{Admission rates}

The national age-standardized rates of hospitalization are 46 for planned admissions and 56 for urgent hospitalizations/per 1000 inhabitants. Comparing the age-standardized rates of hospitalization, in all regions, the urgent admissions exceed the planned ones with the only exception of Lombardia $(-9 \%)$. In all Italian regions emergency admissions have higher average age than planned ones, with the exception of Campania, Puglia, Calabria and Sicilia, where they are lowest (respectively $-5 \%-1 \%-2 \%$ and $-6 \%$ ). Liguria is the region which has the widest gap in average age for emergencies, being higher by $20 \%$ than that of planned admissions, followed by Toscana (17\%) and Emilia Romagna (16\%) (Figure 1). The regional vari- 
ability, and the usual (for the National Health Service) North-South gradient is confirmed, showing a distribution with prevalent emergency admissions for Piemonte region (planned 44 and urgent 47/1000 inhabitants), Emilia (planned 56 and urgent 58/1000 inhabitants), Toscana (planned 49 and urgent 50/1000 inhabitants) and Marche (planned 48 and urgent 48/1000 inhabitants). Valle d'Aosta and Provincia Autonoma di Trento along with Calabria and Sardegna are those with more predominance of emergency hospitalizations. The correlation between rates of emergency standardized hospitalization and length of stay (LOS) less than four days is significantly positive, highlighting the existence of risks of admissions inappropriateness and, indirectly, inefficiency of primary health care in the field.

\section{The average length of hospital stay}

The average LOS of urgent hospitalization exceeds planned admissions in all regions (Figure 2). The deviation from the national average LOS for urgent admissions and those for planned admissions is again very dissimilar. Emilia Romagna, Toscana and Umbria have a lower LOS for both the urgent and planned admissions, the gap ranges from 0.20 days to 0.87 . Different regions exceed the national average. Veneto stands out as it has a LOS 1.40 days higher for urgent and 1.24 for planned admissions. There are also regions that have opposite deviations for the two types of hospitalization. In particular, Piemonte has a LOS for urgent admissions which is more than 1.46 days compared to the national average and less than 1.17 days, for planned admissions.

\section{Admissions value}

The hospitalization economic value has been calculated using the national tariffs nomenclature (decree D.M. 18 Ottobre 2012). ${ }^{8}$

The total value of urgent admissions is 12,760 billion $€$ against 11,180 billion $€$ of planned admissions. If we test what happens at regional level and measure the complexity of admissions by calculating the average value for all regions, we can see that the national average is $3682.19 €$ for emergency admissions, compared to $4083.42 €$ for planned admissions. Deviations from the average range for emergencies admission vary from $+516 €$ and $-509 €$ (Figure 3) represented by Piemonte and Provincia Autonoma di Bolzano respectively. For planned admissions the variability of complexity ranges between $+622 €$ of Liguria and $-453 €$ of Sardegna compared to the national mean (Figure 3).

\section{Role of Internal Medicine in the management of emergency admissions}

The top eight wards receiving most of the patients from emergency admission are the following in descending order: Internal Medicine (General Medicine),

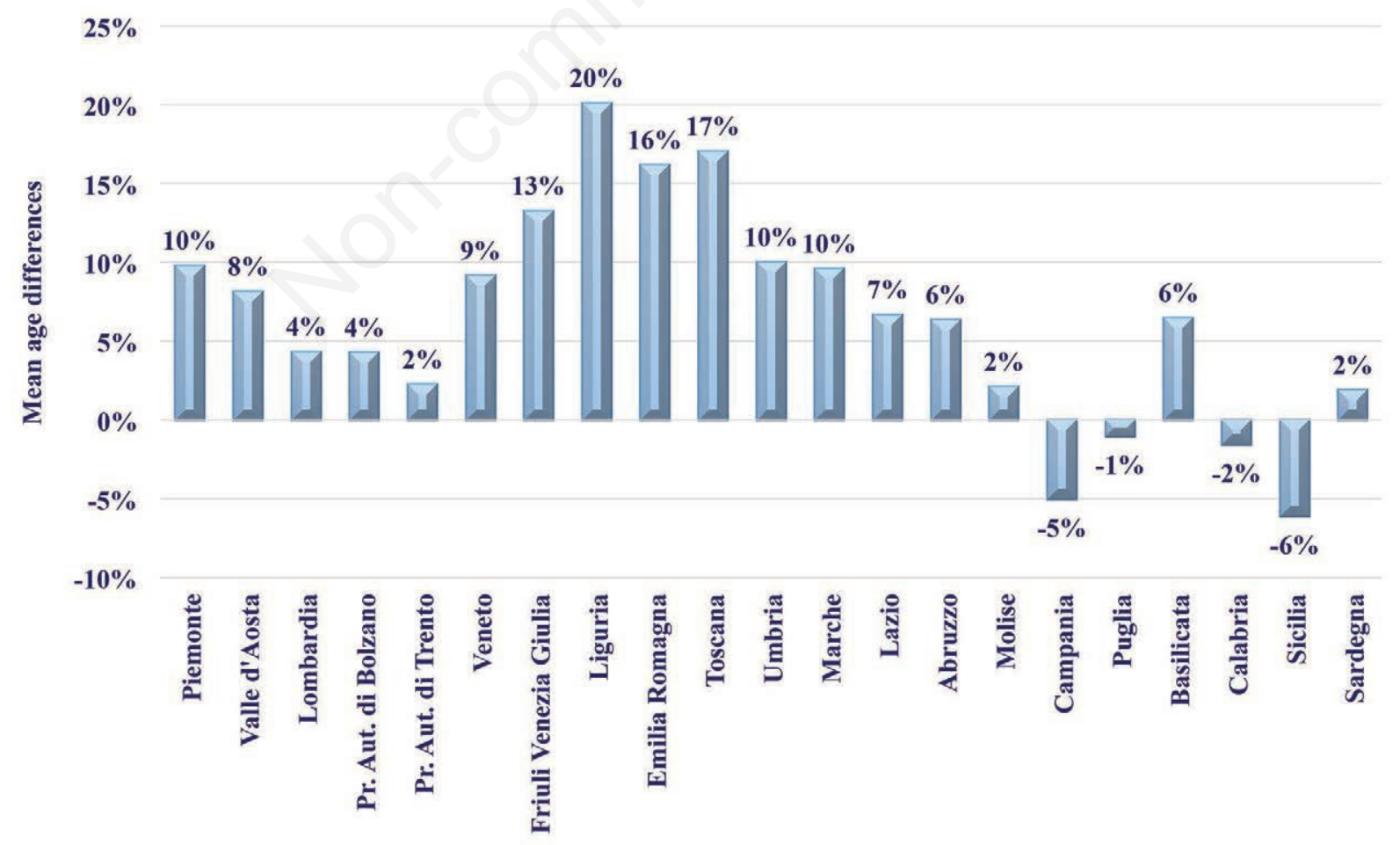

Figure 1. Mean age differences of urgent admissions compared to planned ones in Italian Regions. Data source: 2013 SDO data processing by C.R.E.A. Sanità. 
General Surgery, Orthopedics, Cardiology, Pediatrics, Obstetrics and Gynecology, Neurology and Geriatrics.

Internal Medicine seems to have the most important role in the management of emergency hospitalizations, covering $27 \%$ of admissions from ER. Other departments also have important roles: the General Surgery manages $10 \%$ of emergency hospitalizations, Orthopedics and Cardiology both $8 \%$. 7\% of emergency patients are treated by Pediatrics, and $6 \%$ by the Obstetrics and Gynecology wards. Although increasing, Neurology and Geriatrics receive less patients coming from ER (4\% and 3\% respectively) (Figure 4).

Very interesting is the comparison between medicine and surgical area on the impact of admissions in emergency as shown in Table 1.

\section{Relationship between use of urgent hospitalization and patient age}

In 2013 SDO at national level the average age of patients for planned hospitalizations ranged from 53 to 59 years and between 53 and 65 years for admissions from the ER.

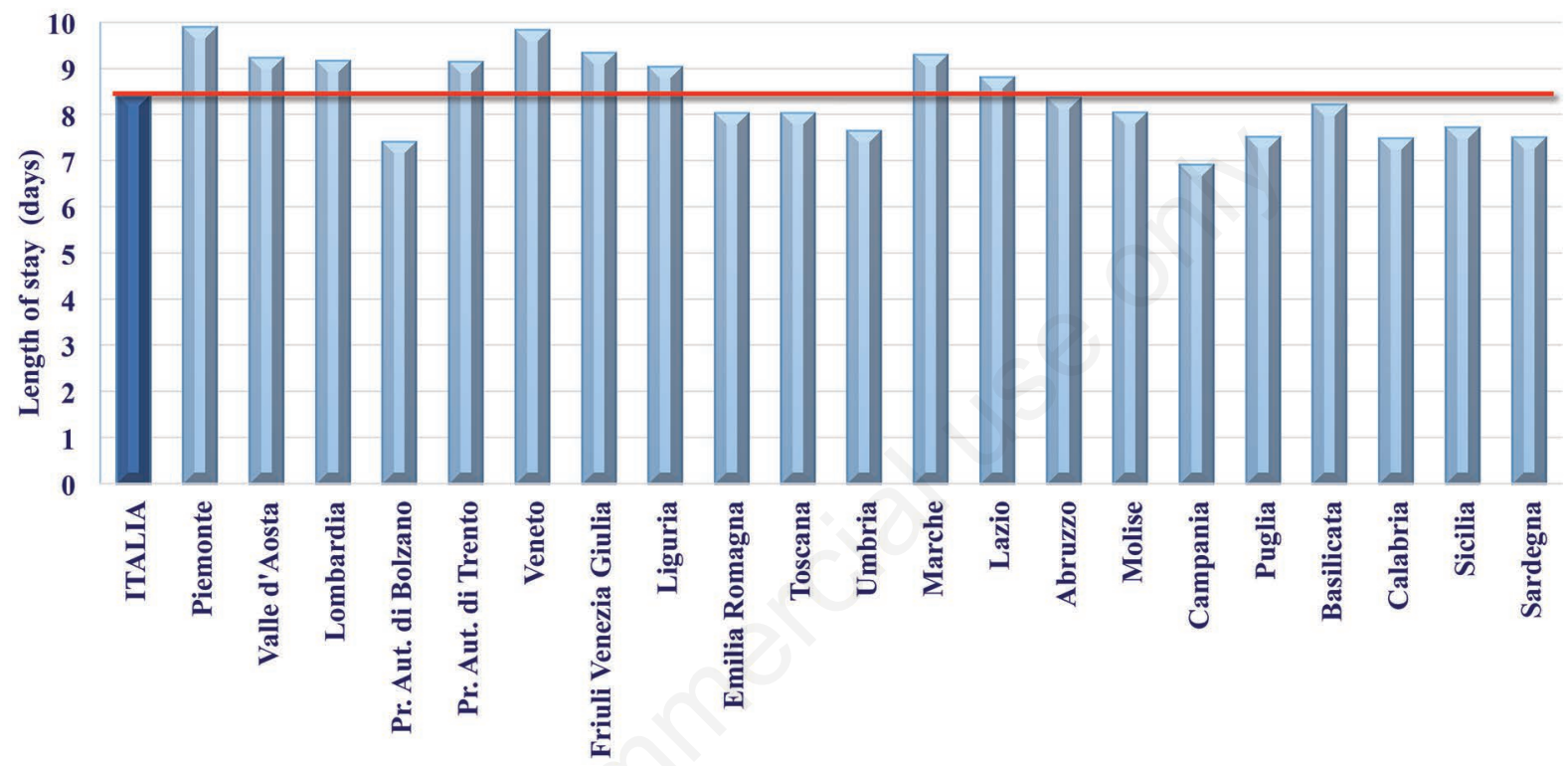

Figure 2. Emergency admissions length of stay. Data source: 2013 SDO data processing by C.R.E.A. Sanità.

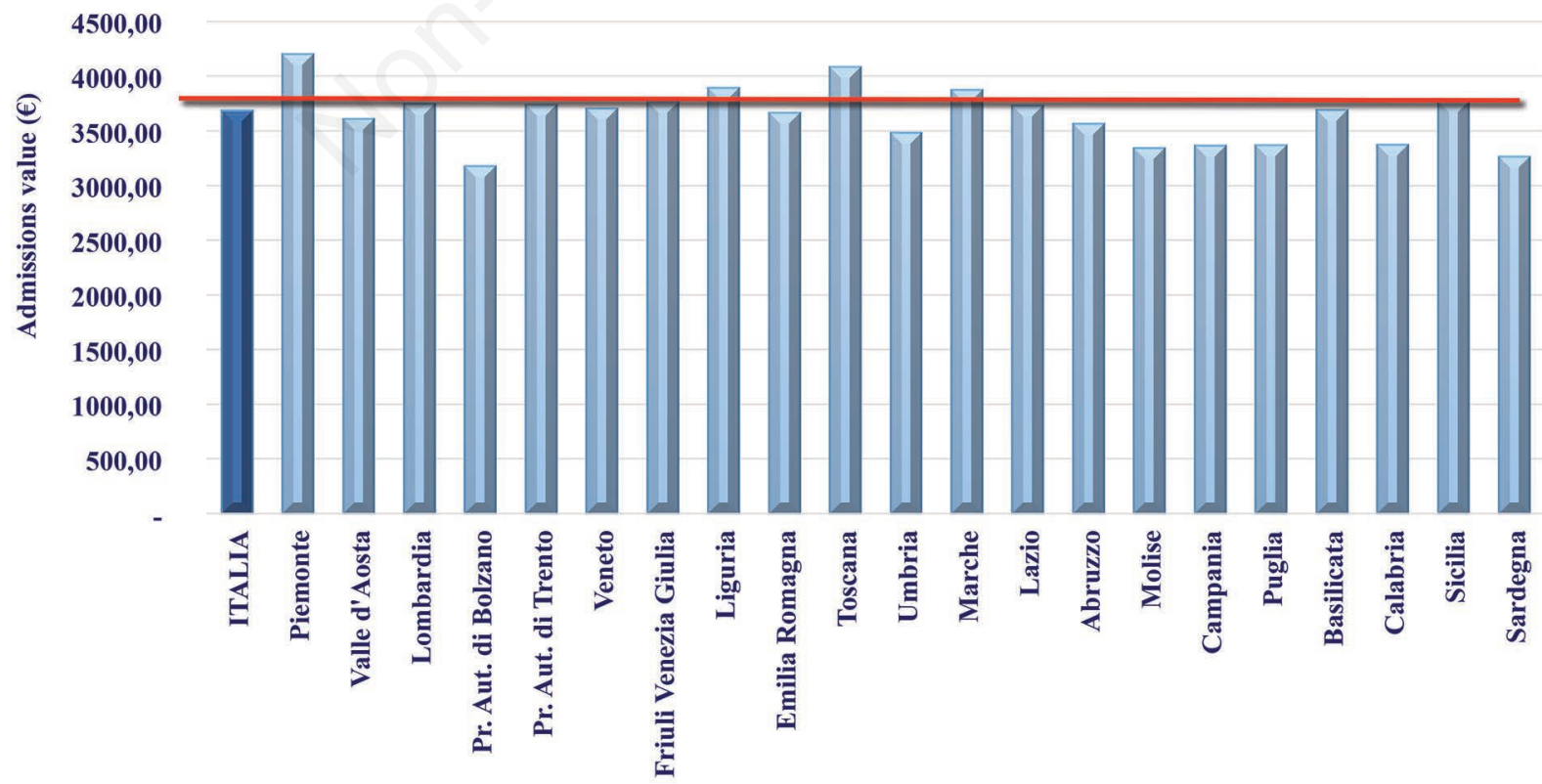

Figure 3. Average value of emergency admissions. Data source: 2013 SDO data processing by C.R.E.A. Sanità. 
In all regions, with the exception of Campania, Puglia and Sicilia, urgent hospitalizations show an average age higher than the other. In the North, the phenomenon is more evident, especially in Liguria, Emilia Romagna and Toscana for which the differences are of about 10 years between one and the other (Figure 5).

To analyze the influence of age on admission five age classes were defined: i) 1-14 years; ii) 15-39 years; iii) 40-64 years; iv) 65-74 years; v) more than 75 years.

Patients entering the hospital using the emergency department are mostly elderly (Figure 6).

For Internal Medicine, Orthopedics and Cardiology emergency admissions focus mainly on the age group of over 75 , representing $60 \%, 42 \%$ and $43 \%$ respectively. The General Surgery is the only one that is interested in equal measure, and significantly, from emergencies for patients aged over 75 and aged 40-64.

The phenomenon of the massive presence of eld- erly patients in ER admissions, compared to those planned, is very evident in IM. Internal Medicine presents $60 \%$ of patients over 75 admitted in emergency, while in the case of planned hospitalization only $41 \%$ is over 75 years of age. The General Surgery instead passes from $30 \%$ to $17 \%$ going from urgent to planned admissions. Also for the Orthopedics (42\% urgent and $15 \%$ planned admission) there is a notable difference. There is a much milder effect on Cardiology where admissions of people over 75 account for $43 \%$ of urgent admissions and $33 \%$ of those planned.

The class of 75-64 years is uniformly represented by all subjects and by the two types of hospitalization (urgent and planned).

The class of 40-64 years instead has an exactly opposite trend compared to that of over 75. In emergency the percentages of hospitalized patients are lower than those of the planned admissions. This is always valid for all four wards considered.

Table 1. Medicine and surgical area impact of admissions in emergency.

\begin{tabular}{lcccc}
\hline Emergency admissions typology & Cases (no.) & \% on total & Value (€) & $\begin{array}{c}\text { Average DRG } \\
\text { (cost by admission in } \boldsymbol{\epsilon})\end{array}$ \\
\hline Surgical & 744,019 & $23 \%$ & $5,167,380.93$ & 6945.23 \\
\hline Medicine & $2,559,681$ & $77 \%$ & $7,002,010.16$ & 2735.50 \\
\hline Total & $3,305,103$ & $100 \%$ & $12,169,391.09$ & 3682.19
\end{tabular}

Note that the discharged from the Internal Medicine are $42 \%(1,073,525)$ of the admissions related to medicine (medical area). DRG, diagnosis-related group.

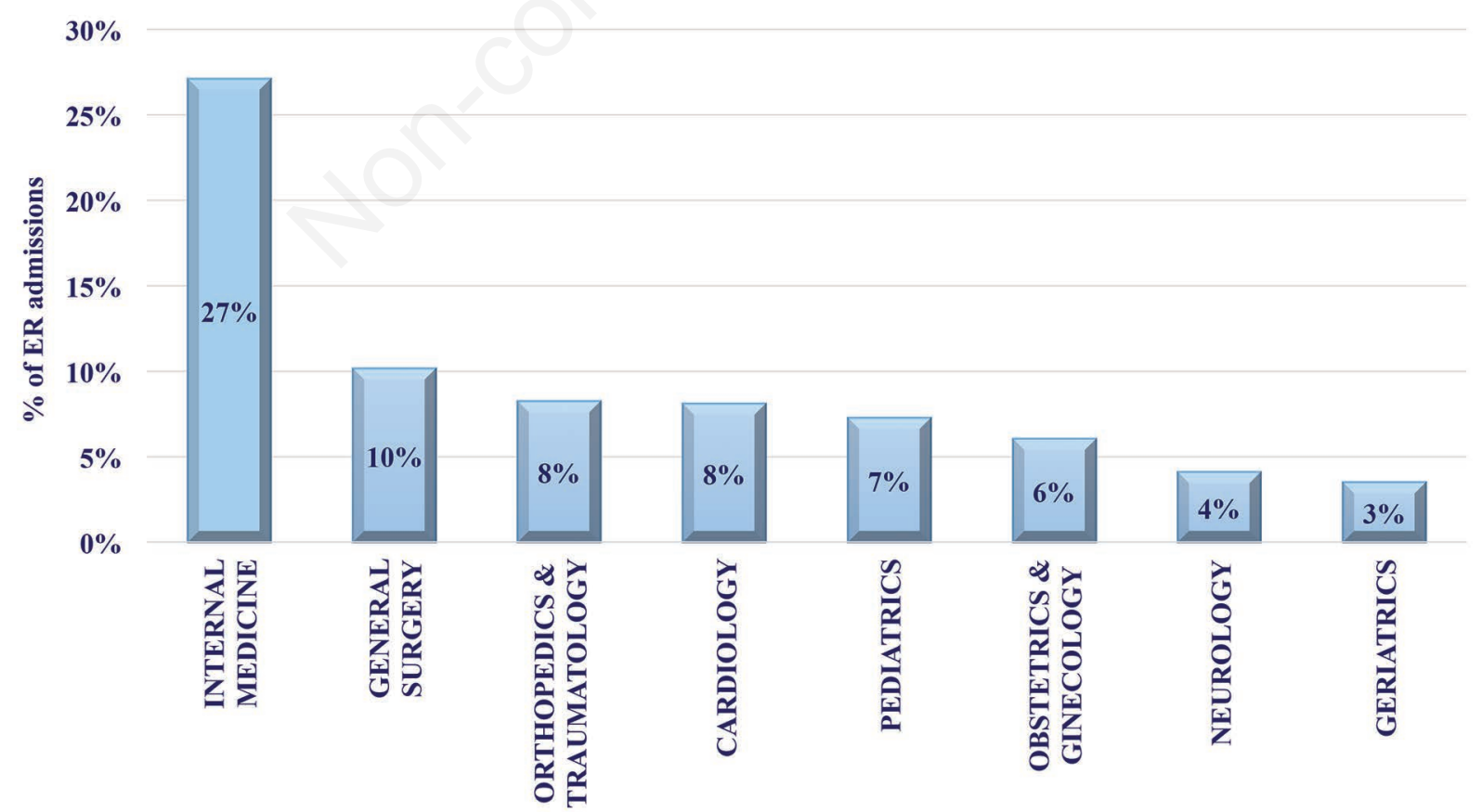

Figure 4. Typesetting of admissions in Emergency Room (ER) according to discharge specialties. Data source: 2013 SDO data processing by C.R.E.A. Sanità. 
The highest number of hospitalizations in emergency is between 65 and over 85 years old (Table 2).

The age greatly increases the length of stay, as shown by the data of admissions both for urgent and planned ones. Patients over 85 years old, representing $13 \%$ of planned admissions, show an average LOS of 9.71 days compared with that of 5.57 for patients between 15-39 years of age.

\section{Internal Medicine source of admissions: comparison with other specialties}

The national figure indicates that $83 \%$ of admissions to Internal Medicine come from the Emergency Department compared with $17 \%$ of planned admissions. The data are significantly different from those of other specialties such as Cardiology, in which 57\% of admissions are in emergency and $43 \%$ are planned, and Surgery where only $37 \%$ of hospitalizations are in emergency while $63 \%$ are planned. This datum confirms that the support of Internal Medicine is mainly in the Emergency, contributing significantly in the management of the Emergency Department activities, reducing overcrowding by constant bed supply.

\section{Relationship with primary health care/field facilities offer and emergency admissions demand}

Examining the percentage of admissions in IM coming from the ER allows us to speculate the role of the non hospital facilities in determining the demand for emergency admissions. The data analyzed show that the duration of hospitalization decreases in regions with efficient/well organized primary care facilities.

Looking at the Italian regions, where the health system is better able to efficiently respond to the needs of the population, and in which primary care is organized to provide appropriate management of chronic

Table 2. Effect of age on percentage of total ordinary emergency and planned admissions and average length of stay.

\begin{tabular}{lcccc}
\hline \multicolumn{1}{c}{ Emergency } & \multicolumn{2}{c}{ Planned } & & \\
\hline Age (years) & \% of admissions & Average LOS (days) & \% of admissions & Average LOS (days) \\
\hline $15-39$ & 4 & 6.31 & 7 & 5.57 \\
\hline $40-64$ & 17 & 8.64 & 29 & 6.76 \\
\hline Over 65 & 79 & 9.89 & 64 & 8.78 \\
\hline $65-74$ & 19 & 9.83 & 23 & 7.91 \\
\hline $75-84$ & 33 & 10.18 & 28 & 9.06 \\
\hline Over 85 & 27 & 9.55 & 13 & 9.71
\end{tabular}

LOS, length of stay.

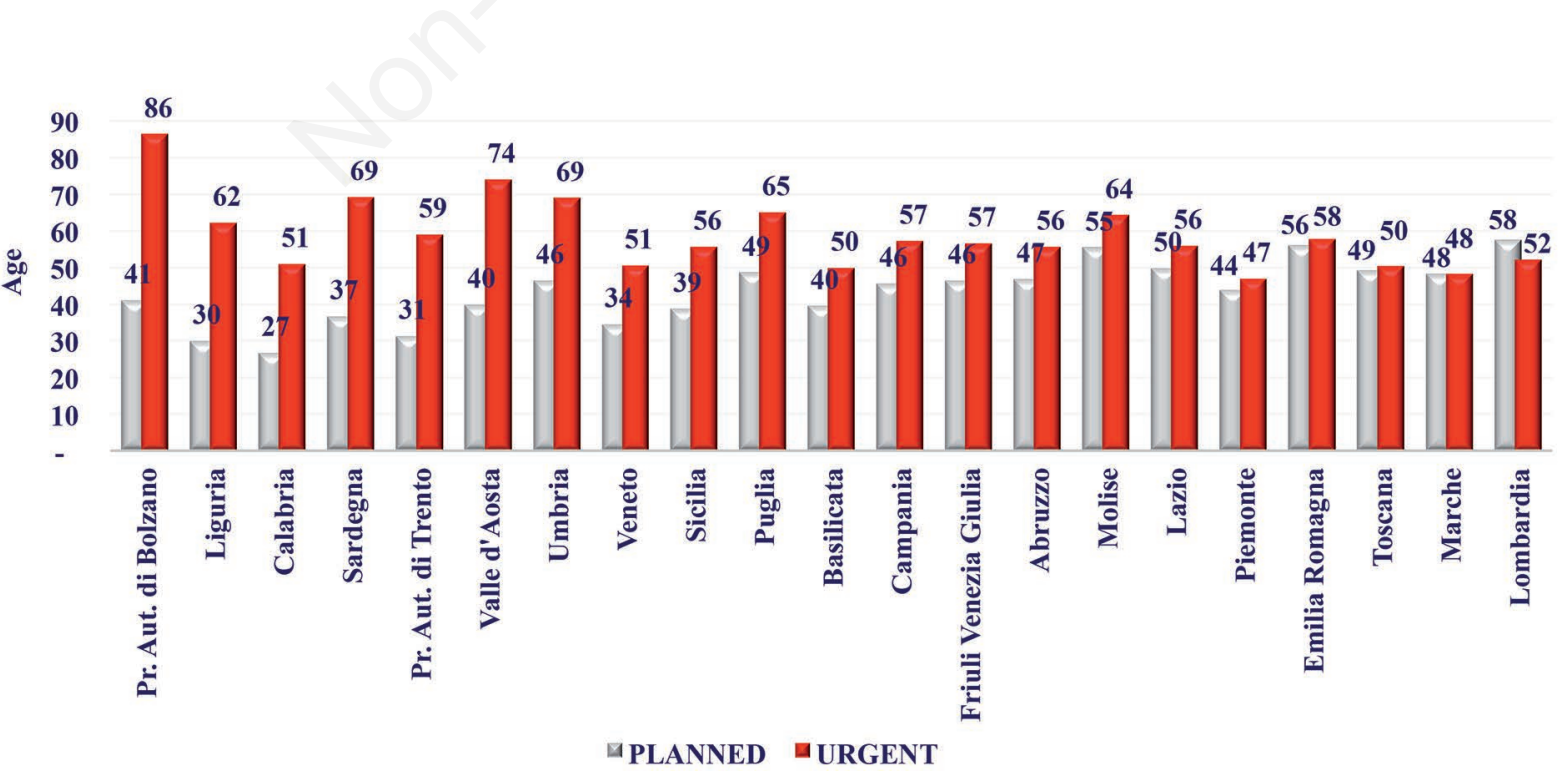

Figure 5. Average age of emergency and planned admissions in the Italian regions. Data source: 2013 SDO data processing by C.R.E.A. Sanità. 
disease in the stability phase, we note that the percentage of hospitalizations in emergency admitted to Internal Medicine is unexpectedly high. In Emilia Romagna in fact we have $86 \%$ of admissions in Internal Medicine coming from the ER with an average stay of 8.74 days less than the average Italian LOS. The average LOS increases with the increase in the age of patients, with inpatient admissions reaching 10.18 days for those over 85 years. These findings suggest that the primary care facilities more effectively enable hospital patient to be discharged quickly, but hardly could change the percentage of patients admitted in emergency to IM.

Similarly in Toscana, which is also a virtuous region, the origin of the ER admissions to IM is $90 \%$ with a mean length of stay of 8.26 days, which is also below the national average. There seems to be little correlation between efficiency of primary care facilities and admissions to Medicine: perhaps the patients are hospitalized more appropriately, selecting only real emergencies, but still they represent an incompressible percentage of admissions. Lazio, a region in the repayment plan, presents poorly organized non hospital facilities that are unable to meet citizens health needs. In addition, being in deficit, choices in health care management are limited. This reduced performance of the regional health system is documented by the average LOS in IM equal to 9.74 days, which appears above the national average. Unexpectedly despite the reduced performance, the urgent admissions are only $78 \%$ of the total admissions. This is difficult to explain when comparing with the other Italian regions with better health performance. The Lazio region scenario confirms that the average LOS mirrors the increasing age of patients, with an average of 7.43 days for patients between 15 and 39 years of age and an increase to 11 days for those between 75 to 84 .

However the percentage of urgent admissions seems to be unaffected by these services due to the number of patients requiring admissions for acute or complex conditions. This is driven primarily by complex elderly patients during exacerbation of the disease that cannot be treated in the primary care structures, but require hospitalization with high technological impact and intensive care.

Table 3 is a synopsis of the different national and regional performance indicators analyzed in the article. $^{9-12}$

\section{Discussion}

To evaluate hospital functionality and the complex relationship between hospital and primary care services we analyzed hospital discharge records, focusing on the modality of hospital admissions. We evaluated types of hospitalizations, patients demographics and clinical features.

Emergency admissions are a fundamental part of hospital care and are indirect indicators of hospital management. They directly impact ER efficiency and the increased need of beds for urgent admissions is evidence of a severe problem of overcrowding.

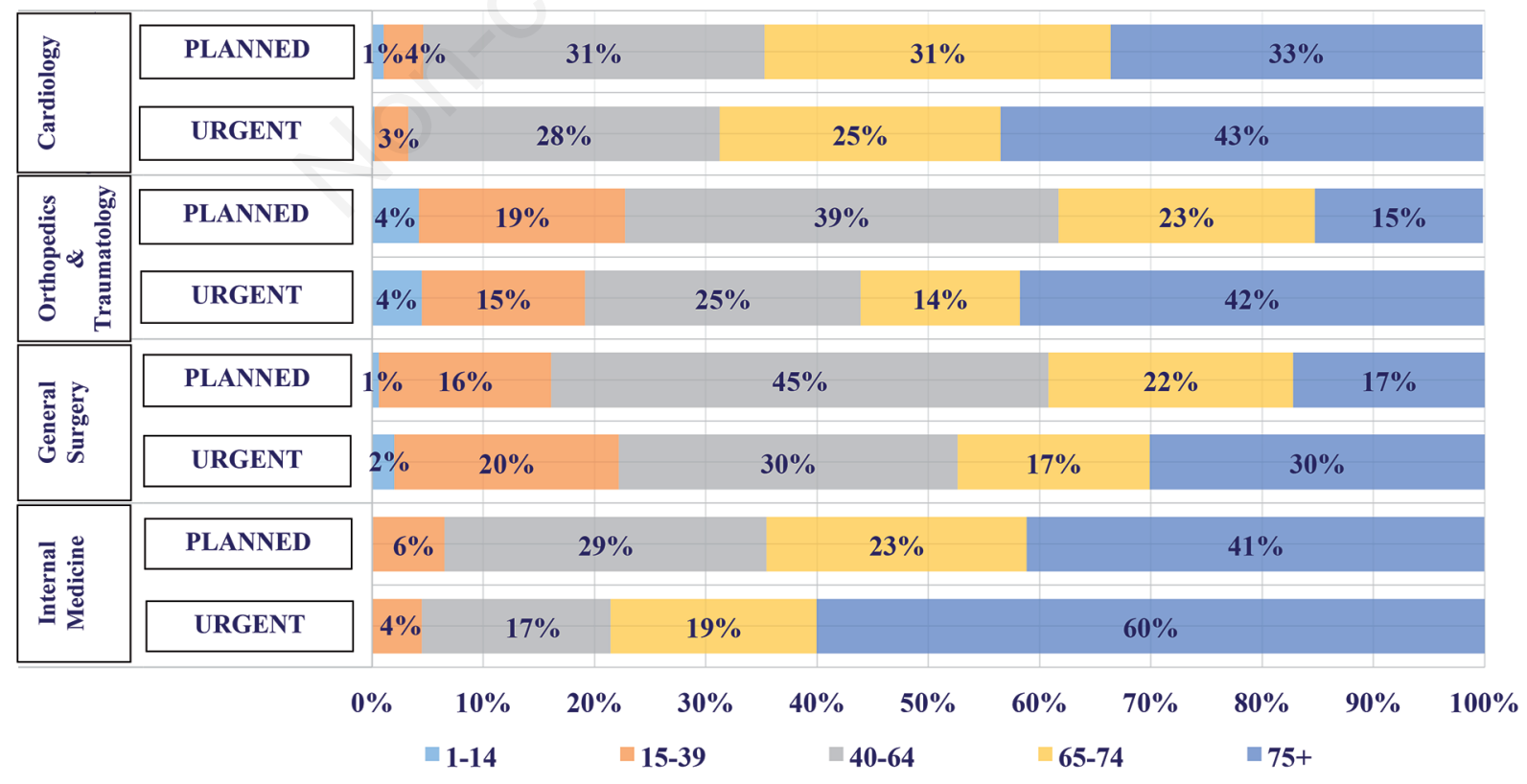

Figure 6. Age distribution of urgent and planned admissions according to the discharge's specialties. Data source: 2013 SDO data processing by C.R.E.A. Sanità. 
This study has provided the analysis of ER's contribution to hospital care efficiency in terms of admissions and the IM's contribution in managing acute patients needing emergency admissions.

\section{Admission rates}

The first result of our analysis is that in Italy $55 \%$ of hospitalizations occurs via ER. The different role of ER in terms of admissions at regional level can have a significant weight in the comparability of the data, considering also the attractiveness indexes, which enhance the differences in the regions in excess of passive mobility. The major differences in the hospitalization rates in favor of emergency are observed in regions characterized by a mountainous field, which could make more difficult the access to hospitals, and in Liguria, known as the region with a higher average patients'age. The excessive use of emergency admissions can also be a symptom of the inefficiency of the system of taking care of the patients. It might be suggested by the high values encountered in different regions of the South. Note that there is rather high percentage of admissions followed by low LOS (conventionally less than four days) at risk of inappropriateness.

It seems, from this first analysis, that major differences between urgent and planned admissions are observed in the regions considered not very efficiently organized, as if the field facilities would put a filter to hospital access.

This study further indicates that major determinant for hospitalization through ER is old age and the complexity of patients with acute conditions. These two elements differentiate urgent admissions from planned ones.

The hypothesis to be verified is that this patients often present complex diseases that have no other alternative than to be treated in hospital. Additionally, family members or care givers are unable to cope with such acute phase of disease.

The increasing ageing and the progressive disappearance of the informal care giving, able to take care of the growing number of elders, make it difficult to contain the increasing presence of old and complex patients in ER.

\section{The average length of hospital stay}

Preliminary data, of non-univocal interpretation, suggests that one of the factors that can modify the LOS is the presence of non-hospital facilities in the field that, by receiving patients in an early stage of stabilized disease, contribute to efficiently reduce the hospital LOS. ${ }^{13}$

Indeed, even the regions presenting better indicators related to primary care facilities and hospital organization do not show better indicators compared to other regions in terms of percentage of emergency ad-

Table 3. Comparison between national and regional performance indicators: synoptic.

\begin{tabular}{|c|c|c|c|c|c|}
\hline Area & Regions & $\begin{array}{l}\text { Emergency } \\
\text { and planned } \\
\text { admissions }\end{array}$ & $\begin{array}{c}\text { Emergency } \\
\text { admissions } \\
\text { length of stay }\end{array}$ & $\begin{array}{c}\text { Emergency } \\
\text { admissions } \\
\text { value }\end{array}$ & $\begin{array}{c}\text { Average age of } \\
\text { emergency } \\
\text { admissions }\end{array}$ \\
\hline Italy & $\begin{array}{l}\text { Plannec } \\
\text { Emergen }\end{array}$ & $\begin{array}{l}\text { d: } 46 / 1000 \text { inhabitants } \\
\text { cy: } 56 / 1000 \text { inhabitants }\end{array}$ & 8.5 days & $3682.19 €$ & $\begin{array}{c}\text { Emergency: } 59.8 \text { years } \\
\text { Planned: } 56.4 \text { years }\end{array}$ \\
\hline \multirow[t]{9}{*}{ North } & Valle d'Aosta & ++ & + & - & + \\
\hline & Piemonte & $=$ & ++ & ++ & + \\
\hline & Lombardia & -- & + & $=$ & - \\
\hline & Provincia Autonoma di Bolzano & +++ & --- & --- & $=$ \\
\hline & Provincia Autonoma di Trento & + & + & $=$ & $=$ \\
\hline & Veneto & - & ++ & $=$ & + \\
\hline & Friuli Venezia Giulia & $=$ & + & $=$ & ++ \\
\hline & Liguria & + & + & + & ++ \\
\hline & Emilia Romagna & $=$ & $=$ & $=$ & ++ \\
\hline \multirow[t]{6}{*}{ Center } & Toscana & - & $=$ & ++ & ++ \\
\hline & Umbria & ++ & - & - & + \\
\hline & Marche & - & + & + & + \\
\hline & Lazio & $=$ & + & $=$ & - \\
\hline & Abruzzo & $=$ & $=$ & - & - \\
\hline & Molise & + & - & - & - \\
\hline \multirow[t]{6}{*}{ South } & Campania & $=$ & --- & -- & -- \\
\hline & Puglia & + & -- & -- & -- \\
\hline & Basilicata & - & $=$ & $=$ & $=$ \\
\hline & Calabria & - & -- & -- & -- \\
\hline & Sicilia & $=$ & $=$ & $=$ & -- \\
\hline & Sardegna & ++ & - & -- & - \\
\hline
\end{tabular}

+ and - indicates the grading of deviation from the national average; = means the same value of the national average. 
missions compared to planned. Certainly where the primary care organization is strengthened there is a reduction in hospitalization and LOS compared to the national average, but the relationship is not as strong as it would be expected.

This is confirmed by the high percentage of urgent admissions in regions where primary care facilities accelerate hospital discharge from the hospital, but also select, probably more appropriately, acute cases requiring hospitalization.

An efficient complementarity between primary care facilities and hospital care in managing poly-pathological complex patients, which evolve from the chronic phase (manageable outpatient) to the acute one (requiring technological devices and full time care that only the hospital can ensure), seems to be missing. The high percentage of admissions by ER in IM (83\%), mainly in old age, shows that there is a constant percentage of patients who become acute and require hospitalization for unstable medical conditions that can not always be treated in primary care facilities, even if well organized. In fact, the hospital at home as that provided in Piemonte, ${ }^{14}$ can be effectively achieved as an alternative to hospitalization only for patients suffering from diseases in acute phase not requiring high technological equipment or intensive/invasive monitoring. ${ }^{15}$

Furthermore, our analysis clearly shows that the IM receives the majority of urgent admissions (27\%), thus being the main ward handling hospitalized acute patients annually.

\section{Value admissions}

Considering that the national average is $3682.19 €$ for emergency admissions, compared to $4083.42 €$ for planned admissions, the regions with greater complexity seem to be Veneto and Marche, both for urgent admissions and for planned ones. Observing the admission value of southern regions it would appear that these regions manage less complex cases. Moreover, where the complexity of planned admission is higher than the national average, it is less for the urgent admissions, mainly in regions such as Provincia Autonoma di Trento, Veneto and Liguria. Even if there are regional differences, the mean value of Internal Medicine DRGs is high, because is directly related with the complexity of cases. In fact, among the first DRGs in IM we found cardiac failure, pulmonary edema, sepsis occurring in patients aged with multiple active diseases. According to a 2009 pan-European study performed by the Young Internists Research Network of the European Federation of Internal Medicine on 1501 patients from 31 physicians in 18 European countries, the patients admitted to IM carried an average of $2.75(+/-2.22)$ chronic medical diagnoses, ranging from 0 to 18 . The most common presenting complaint was shortness of breath, followed by chest pain and abdominal pain. A cardiac condition was most common, followed by infectious disease. The complexity of patients averaged $2.5(+/-1.14) .{ }^{16}$ This European evidence confirms the need of technology, continuous monitoring, adequate nursing assistance and competent medical personnel to treat patients admitted in Internal Medicine wards and that the DRGs are only partially able to quantify it.

\section{Role of Internal Medicine in the management of emergency admissions}

The strong impact of the IM on the management of urgent admissions can be partly explained by the fact that the IM is present in all hospitals with a high number of beds, while the specialized wards (Geriatrics, Neurology, Pediatrics, etc.) are less well represented and have a lower number of beds. According to the Literature ${ }^{17-19}$ Internal Medicine admits mainly complex DRG related to Neurology, Cardiology as well as to the Geriatrics. Older age, together with polypharmacy, non use of formal and/or informal home-help services, history of falls, temporal disorientation, place of living and use of psychoactive drugs contribute significantly to determine the hospital admission through ER.

\section{Role of Internal Medicine in the future hospital}

Regarding projections about the global burden of diseases in the coming years it is clear that it will consist of cardiovascular disease and cancer. ${ }^{20}$

In view of the progressive increase in life are we sure that these complex and elderly patients in the acute phase of their multiple diseases could be treated in the primary care facilities and not in hospital settings?

Surely the chronicity costs are moving forward, but the complexity of the disease and comorbidities are likely to cause repeated exacerbations requiring hospital care and high technology devices. ${ }^{21,22}$

The preliminary results in this study are in accord with the recommendations for the future hospital published in 2013 by the Royal College of Physician ${ }^{6}$ that explores different issues, from staff standards to relationship with patients, care objectives, good clinical practice and economic sustainability of health care. They affirm that hospital care should be guaranteed seven days a week, being patient-centered with a team of specialists looking after the patient until his clinical conditions need it. Complex patients, in particular, may require more specialists, but all of them coordinated by a consultant, often an internist who will also decide when the patient does not need hospital care anymore, according to predefined and simple criteria. The level of care should be adequate to acuity and complexity of the clinical picture; there should be more space for acute medical patients and the number of nursing staff should be proportioned to the patient 
clinical needs. A team of internists should look after all the hospital medical patients, included those in surgical wards with an adequate re-distribution of resources between surgical and medical wards.

On the basis of daily medical practice that registers a constant increase in poly-pathological complex patients, who require hospitalization for clinical instability in case of acute diseases and whose care is fragmented in multiple specialized interventions with movements from one ward to another, a very recent new model for the hospital management of acute complex patients was presented, called acute complex care model (ACCM). ${ }^{23}$ ACCM represents an organizational approach tailored to acute complex, poly-pathological patients who are at high risk of inappropriate admissions or exaggerated resource consumption, in the absence of the multi-professional coordination and risk-benefit assessment of care that only an internist can provide.

The name just recalls the chronic care model (CCM), designed for the de-hospitalization of chronic patients by preventing acute exacerbations. As CCM, the new model is patient-centered, includes a multidisciplinary approach and extensive use of informative system and aims for continuity of care. The two models are not in contrast, but complementary. The ACCM represents the hospital counterpart of the CCM and combines it with the concept of Acute Medicine, best defined as that part of hospital medicine concerned with the immediate and early specialist management of adult patients suffering from a wide range of medical conditions requiring urgent or emergency care. Bell et al..$^{24}$ defined the Acute Medical Unit (AMU) as medical wards staffed and equipped to deal exclusively with acute medical patients transferred from emergency department or community for rapid specialist medical and multidisciplinary assessment and treatment. ${ }^{25-27}$ Those patients who can be stabilized, treated and discharged are managed efficiently in AMU. ${ }^{28}$ Key to this is the close co-operation and mutual respect between the complementary specialties. The evolution represented by ACCM is the focus on complex poly-pathological patients and the pivotal role of internists in the hospital care.

\section{Learning points}

Learning points can be resumed as follows: i) $55 \%$ of Italian hospital admissions are in emergency; ii) the major determinants for urgent admissions are the old age and the complexity of acute conditions of patients; iii) the differences between emergency and planned admissions are less evident where there is a regional network efficiently organized; iv) admissions in IM represent $27 \%$ of emergency admissions and come from ER in the $83 \%$ of cases documenting a prevailing management of acute complex patients.

\section{Conclusions}

The definition of the Internal Medicine role needs to be connected to health economics, in order to affect the choices of health policy in planning health reforms, according to an authoritative opinion, avoiding as much as possible to be subjected to them. This study, realized on SDO analysis, was designed with the aim to better understand the economic impact of IM in hospital activities, and the IM in answering to the patients needs according to the changing demographic scenario, the patients characteristics, the frequency of diseases, the impact of comorbidities in patients admitted and the primary care facilities efficiency.

Since $55 \%$ of hospital admissions in Italy are urgent, IM receives $27 \%$ of the total emergency admissions and $83 \%$ of the IM admissions comes from ER, the prevailing activity in IM Departments is acute complex patients care.

The first 10 IM DRGs (among which cardiac failure, acute respiratory failure, sepsis, stroke, renal failure) include several acute and complex diseases, unmanageable by single organ specialists and requiring the specialist of complexity with transversal skills, the Internist.

According to the SDO analysis the role of IM appears to be central in urgent admissions and in the management of the acute complex patients who seem to be the main driver of hospital admissions in emergency. It is reasonable to think that the new role of hospital IM is to coordinate and integrate multi-disciplinary interventions, including organ specialists, nurses and other professionals to cover health needs in the intra-hospital tracks of the acutely ill complex and poly-pathological patients.

The reorganization should therefore be addressed foreseeing IM wards enhancements, the process re-engineering and the redistribution of resources. All this in order to improve results, maintaining a minimum size required to cope with a constant need and difficult to contain, looking for the benefit of the user/patient.

\section{References}

1. Alessandri M, Bartolomei C, Bernardini M, et al. Role of internal medicine in a new model of hospital: a proposal of Tuscany's FADOI. Ital J Med 2007;1:65-9.

2. Nardi R, Berti F, Fabbri LM, et al. Towards a sustainable and wise healthcare approach: potential contributions from hospital Internal Medicine Departments to reduce inappropriate medical spending. Ital J Med 2013;7:65-81.

3. Scotti E, Pietrantonio F. The hospital Internal Medicine specialist today: a literature review andstrength, weaknesses, opportunity, threats (SWOT) analysis to develop a working proposal. Ital J Med 2013;7:278-86.

4. Ministero della Salute. Rapporto annuale sull'attività di ricovero ospedaliero. Dati SDO 2014; giugno 2015. 
Roma: Dipartimento della Programmazione e dell'Ordinamento del Servizio Sanitario Nazionale Dir. Gen. della Programmazione sanitaria Ufficio VI; 2015. Available from: http://www.salute.gov.it/portale/temi/p2_4. jsp?lingua $=$ italiano\&tema $=$ Assistenza, $\% 20$ ospedale $\% 2$ $0 \mathrm{e} \% 20$ territorio\&area $=$

5. Federazione Italiana Aziende Sanitarie e Ospedaliere (FIASO). I sistemi di finanziamento regionali delle Aziende Sanitarie e Ospedaliere. Modalità di riparto dei fondi sanitari regionali per gli anni 2011 e 2012; febbraio 2015. Ed. KOS Comunicazione e servizi s.r.l.; 2015. Available from: http://www.sossanita.it/doc/2015 02_FIASOfinanziamentoREG_ASL_AO.pdf

6. Royal College of Physician. Future Hospital: caring for medical patients; September 2013. London: Future Hospital Commission; 2013.

7. Ministero della Salute. Rapporto annuale sull'attività di ricovero ospedaliero. Dati SDO 2013; luglio 2014. Roma: Dipartimento della Programmazione e dell'Ordinamento del Servizio Sanitario Nazionale Dir. Gen. della Programmazione sanitaria Ufficio VI; 2014.

8. Ministero della Salute. Decreto 18 ottobre 2012. Remunerazione prestazioni di assistenza ospedaliera per acuti, di assistenza ospedaliera di riabilitazione e di lungodegenza postacuzie e di assistenza specialistica ambulatoriale. (13A00528). In: G.U. Serie Generale n. 23, 28/01/2013.

9. Brandolini A, Saraceno C, Schizzerotto A. Dimensioni della disuguaglianza in Italia: povertà, salute, abitazione. Bologna: Il Mulino; 2009.

10. World Health Organization. Country statistics and global health estimates by WHO and UN partners. Italy statistical profile; 2013. Available from: http://www.who.int/ gho/countries/ita.pdf?ua=1 Accessed: 16/09/15.

11. Indexmundi.com. Italia Tasso di mortalità. Available from: http://www.indexmundi.com/it/italia/tasso_di mortalita.html Accessed: 26/09/15.

12. Agenzia Italiana del Farmaco (AIFA). Rapporto OsMed 2014: l'uso dei farmaci in Italia. Rapporto Nazionale anno 2014. Osservatorio Nazionale sull'Impiego dei Medicinali. Roma: AIFA; 2014.

13. Spandonaro F. $11^{\circ}$ Rapporto Sanità. L'Universalismo diseguale. Roma: C.R.E.A. Sanità; Ottobre 2015.

14. Deliberazione della Giunta Regionale 16 marzo 2010, n. 85-13580 Attività di continuità assistenziale: organizzazione e remunerazione delle attività di assistenza specialistica di ospedalizzazione domiciliare. Regione Piemonte - Bollettino Ufficiale n. 14, 08/04/2010.

15. Roher B. US model for hospital care at home reduces costs and increases patient satisfaction. BMJ 2012; 344:e3997.

16. Duckitt R, Palsson R, Bosanska L, et al. Common diagnoses in internal medicine in Europe 2009: a pan-European, multi-centre survey. Eur J Intern Med 2010;21: 449-52.

17. Bellis P. Progetto Minerva: origini, obiettivi, metodologie. In: AA.VV. Medicina interna. Complessità e metodologia. Vol. 3. Torino: CSE; 2004.

18. Nardi R, Scanelli G, Borioni D, et al. The assessment of complexity in internal medicine patients. The FADOI Medicomplex Study. Eur J Intern Med 2007;18:283-7.

19. Launay CP, Rivière H, Kabeshova A, Beauchet O. Predicting prolonged length of hospital stay in older emergency department users: Use of a novel analysis method, the Artificial Neural Network. Eur J Intern Med 2015; 26:478-82

20. Jones DS, Podolsky SH, Greene JA. The burden of disease and the changing task of medicine. N Engl J Med 2012;366:2333-38.

21. Porcel JM, Casademont J, Conthe P, et al. Core competencies in internal medicine. Eur J Intern Med 2012; 23:338-41.

22. Cranston M, Semple C, Duckitt R, et al. The practice of internal medicine in Europe: organisation, clinical conditions and procedures. Eur J Intern Med 2013;24:627-32.

23. Pietrantonio F, Orlandini F, Moriconi L, La Regina M. Acute Complex Care Model: an organizational approach for the medical care of hospitalized acute complex patients. Eur J Med 2015;26:759-65.

24. Bell D, Skene H, Jones M, Vaughan L. A guide to the acute medical unit. Br J Hosp Med (Lond) 2008;69: M107-9.

25. Subbe CP, Kruger M, Rutherford P, Gemmel L. Validation of a modified early warning score in medical admissions. QJM 2001;94:521-6.

26. Silke B, Kellett J, Rooney T, et al. An improved medical admissions risk system using multivariable fractional polynomial logistic regression modelling. QJM 2010; 103:23-32.

27. Kellett J, Deane B. What diagnoses may make patients more seriously ill than they first appear? Mortality according to the Simple Clinical Score Risk Class at the time of admission compared to the observed mortality of different ICD9 codes identified on death or discharge. Eur J Intern Med 2009;20:89-93.

28. Subbe CP, Bottle RA, Bell D. Acute medicine: triage, timing and teaching in the context of medical emergency admissions. Eur J Intern Med 2011;22:339-43. 